\title{
Natura non facit saltum: Promessas, alcances e limites no desenvolvimento do jornalismo on-line e da hiperficção
}

\author{
Marcos Palacios ${ }^{1}$ \\ Universidade Federal da Bahia \\ palacios49@uol.com.br
}

\begin{abstract}
Resumo: $O$ uso generalizado e efetivo dos recursos de multimidialidade, interatividade e outras potencialidades abertas pelas redes telemáticas para os produtos midiáticos disponibilizados na Internet, parece ter ficado aquém das promessas e expectativas da primeira metade da década de 9o. Vista como um meio que tinha como características centrais a interatividade e a convergência de formatos anteriores, a Internet era apresentada como palco $e$ cenário de transformações revolucionárias, talvez até com a extinção, a médio prazo, das mídias tradicionais. Neste ensaio, explorando alguns aspectos da criação de novas linguagens ajustadas às redes telemáticas, procuramos estabelecer um paralelo entre o desenvolvimento do Jornalismo On-Line e da Hiperficção na Internet. Buscamos situar as especificidades dessas duas tipologias discursivas e esboçar algumas idéias que possibilitem confrontar as promessas de dez anos atrás com a realidade atual. São sugeridas possíveis pistas para uma investigação mais aprofundada de alguns aspectos dessas trajetórias paralelas, porém diferenciadas.
\end{abstract}

\begin{abstract}
The generalized and efficient use of multimidiality, interactivity and other potentialities of digital networks seems to have fallen short of the promises of the early 9o's. Seen as a new medium, characterized by the convergence of previous media formats and by high interactivity, Internet was then portrayed as a stage for revolutionary transformations. Some authors would go as far as announcing the slow but inevitable extinction of traditional media formats. In this essay, dealing with selected aspects of the creation of new languages and forms of expression in digital networks, we try to draw a parallel between the development of Online Journalism and Hyperfiction in Internet. The essay attempts to circumscribe the specificities of the two discursive typologies and sketch some ideas in the confrontation of promises of ten years ago
\end{abstract}

\footnotetext{
${ }^{1}$ Marcos Palacios é doutor em Sociologia pela Universidade de Liverpool, Professor Titular em Jornalismo e docente do Programa de Pós-Graduação em Comunicação e Cultura Contemporâneas e Programa Multidisciplinar em Cultura e Sociedade da Faculdade de Comunicação da Universidade Federal da Bahia.
} 
with present day reality. Some clues are suggested for further investigation of both types of experimentation in Internet.

Resumen: El uso generalizado y eficiente de la multimidialidad, interactividad $y$ otras potencialidades de las redes digitales al parecer no ha logrado acompañar las expectativas y promesas de los inicios de los años 9o. Vista como un nuevo medio caracterizado por la convergencia de formatos de media tradicionales y por su alta interactividad, la red Internet ha sido descrita como escena de transformaciones revolucionarias que, incluso, podrían llevar a la extinción de formatos mediáticos tradicionales. En esto ensayo, se discuten aspectos de la creación de nuevas lenguajes y formas de expresión en redes digitales. Intentamos establecer un paralelo entre el desarrollo del webperiodismo y la ficción literaria en Internet (Hiperficcíon). Hemos buscado delimitar las especificidades de las dos topologías discursivas y esbozar algunas ideas en el confronto entre las promesas de diez años pasados y la realidad actual. Algunas pistas son sugeridas para una profundización de la investigación de las trayectorias divergentes de los dos tipos de experimentación en Internet.

Résumée: Il paraît avoir été en deçà des promesses et des attentes inscrites dans la première moitié des années 9o, l'expression concrète de la "Multimédialité", de l'Interactivité et d'autres potentialités engendrées par les réseaux télématiques pour les produits médiatiques disponibles dans l'Internet. Celle-ci a été présentée comme scène et décor de changements, vraiment révolutionnaires, en aboutissent peut-être avec l'extinction, à moyen terme, des médias traditionnels. Ces tranformations ont été soutenues grâce au regard sur l'internet en tant qu'un moyen porteur de caractéristiques orientées par l'interativité et par la convergence des formats précédents. Nous cherchons dans cet essai établir um parallèle parmi le développement du Journalisme on-line et de l'hyperfiction dans l'internet, en exploitant quelques aspects de la vaste problèmatique liée à la création de nouvelles langages adaptées aux réseaux télématiques. Nous cherchons, aussi, placer les spécificités de ces deux typologies discursives et tracer quelques idées qui facilitent faire le lien entre les promesses d'auparavant et la réalité d'aujourd'hui. Enfin, quelques pistes sont proposées comme possibles chemins qui peuvent aboutir à une enquête plus approfondie, avec une compréhension plus large de cette démarche parallèle, mais également marquée par des aspects différenciés.

Palavras-Chaves: Jornalismo On-line, Hiperficção, Internet

Keywords: Online Journalism, Hyperfiction, Internet

Palabras claves: Webperiodismo, Hiperficción, Internet

Mots-Clés: Journalisme sur Intenet, Hyperfiction, Internet. 
"In the final analysis, hypertext literature may prove to be the desconstructivist critic's secret fantasy realized: a literary genre better known for its literary criticism than for its actual literature."

(Curt Cloninger)

Buscar paralelos entre modelos textuais de diferentes tipologias discursivas (Maingueneau 2001) 2 compartilhando o mesmo suporte midiático estabelece um desafio instigante que pode, eventualmente, lançar luz sobre os desenvolvimentos em curso na busca de construção de novas linguagens. Esta percepção tem sido central nos debates coletivos no âmbito Grupo de Jornalismo Online (GJOL) ${ }^{3}$ da Faculdade de Comunicação (FACOM) da Universidade Federal da Bahia ( $\underline{\text { UFBA) }}$, levando o grupo a seguir com atenção estudos em torno do tema da narratividade no contexto das novas mídias, sem um apego exclusivo à matriz jornalística, mas buscando justamente pontos de intersecção e de distanciamento entre as diferentes tipologias discursivas (jornalismo, literatura, games, webarte etc).

Este ensaio 4 procura sugerir algumas idéias para debate e sintetizar reflexões pessoais a partir de tal abordagem e segue as pegadas de um trabalho anterior sobre o papel do link como elemento paratextual, produzido em parceria com Luciana Mielniczuk (2001), em que buscamos estabelecer paralelos entre a literatura em prosa 5 , em geral, e o jornalismo na produção do discurso hipertextual.

Num texto publicado em 1995, e cujo título poderia ser livremente traduzido como "Porretadas em sua cara: as promessas e armadilhas da Hiperficção", Jürgen Fauth chamou atenção para o fato de que os textos de

\footnotetext{
${ }^{2}$ Conscientes de que a terminologia técnica utilizada em Lingüística e Análise de Discurso apresenta considerável variação entre escolas e autores, decidimos adotar os termos tipologia discursiva ou matriz discursiva, na acepção adotada por Maingueneao (2001), para nos referirmos aos discursos jornalístico e literário que constituem os dois objetos principais desta comunicação.

3 http://www.facom.ufba.br/jol

4 Uma versão preliminar deste trabalho foi apresentada no II Encontro Nacional da Associação Brasileira de Pesquisadores em Jornalismo, Salvador, novembro de 2004. 5 A poesia na Internet seguiu e continua seguindo caminhos muito distintos da prosa literária, merecendo tratamento à parte e escapando aos limites deste ensaio.
} 
hiperficção disponíveis da Internet pareciam desabonar a euforia dos autores críticos do novo gênero que, durante os primeiros anos da década de 90 profetizavam uma verdadeira revolução na literatura. Fauth afirma que, a despeito das promessas grandiosas, a maior parte da hiperficção produzida para a Internet era “desajeitada, pouco satisfatória e de limitado mérito artístico" (1999, p.1).

Além disso, Fauth chama a atenção para uma característica que segundo ele marca o início de toda nova possibilidade midiática: o abuso de alguns dos recursos formais abertos pela nova tecnologia, em detrimento de outras preocupações estéticas. As primeiras gravações em estéreo, - exemplifica ele -, insistiam em reproduzir performances que faziam o som oscilar constantemente entre o alto falante da direita e o da esquerda, assim como os atores de filmes em Terceira Dimensão (3D) - que chegaram a ser grandes sucessos de bilheteria nos anos 50 - estavam sempre brandindo porretes em direção à face dos expectadores. Naqueles filmes, o mais importante eram os sustos pregados na platéia pelos avanços frontais do Monstro da Lagoa Negra ${ }^{6}$ em direção à câmera ou pelo salto de um rato em direção à sala de espetáculo; o enredo que justificava os sustos era de menor monta.

O texto de Fauth soava, naquele momento, como um tanto "reacionário". O que estava ele querendo dizer? Que a Internet não servia como suporte para literatura? Que os autores de ficção não deveriam experimentar com os novos recursos? Não saberia ele que todo processo de criação de novas linguagens passa, quase que necessariamente, por excessos? Não seria de se esperar que tais excessos fossem gradativamente reduzidos até que se alcançasse a "medida certa"?7

${ }^{6}$ O Monstro da Lagoa Negra (The Creature from the Black Lagoon) foi produzido em 1954, dirigido por Jack Arnold. Contava a história de uma horrenda (porém sensível!) criatura que habitava uma lagoa negra na Amazônia. Uma história no estilo King Kong, com a atriz Julia Adams fazendo o papel de objeto de desejo do monstro. Para uma imagem da criatura em $3 \mathrm{D}$ veja: http://crm114.tripod.com/3d/pages/o3.htm usando óculos com uma lente verde e outra vermelha, como os utilizados para os filmes $3 \mathrm{D}$.

7 Uma discussão estabelecendo diferenças entre o excesso e o excessivo pode ser encontrada em Santos (2002) 
Naquele mesmo ano de 1995, Sarah Auerbach afirmava que:

Li muita ficção hipertextual na WWW e me dei conta de que a maioria dela é o que passei a chamar "notas de rodapé melhoradas"; por exemplo, uma história está escrita mais ou menos linearmente, mas quando se chega ao nome de um personagem pode-se seguir um caminho que leva a uma descrição desse personagem, (uma possível variante é um caminho que oferece mais informação sobre uma situação em desenvolvimento). Ler esse tipo de ficção hipertextual pode ser o mesmo que fazer tarefa escolar; a informação periférica, a não ser que esteja colocada de forma muito hábil, pesa no desenvolvimento do argumento normal e dos personagens. E esta é uma das coisas estranhas que notei em grande parte da hiperficção que li: seus autores tentam preservar elementos da ficção linear, como o argumento e os personagens. O hipertexto, de maneira geral, ainda depende do gênero em que nasceu". (AUERBACH,1995, p.1)

Se para Fauth os autores de hiperficção abusavam dos hiperlinks e outros efeitos, - como as imagens mapeadas, GIFs animadas e efeitos de fundo (papéis de parede) -, para Auerbach eles simplesmente abusavam da paciência dos leitores.

Até que ponto a impaciência que transparece nesses escritos era uma forma de intolerância e incompreensão por parte dos dois autores para com os mecanismos de ajuste das expressões então existentes ao suporte que recém se inaugurava? Não seria excessivo e pouco razoável esperar-se que a linguagem das novas mídias já viesse pronta e acabada, acompanhando, como uma espécie de plug-in ou acessório-, a tecnologia de redes digitais?

Estabelecer uma comparação com o desenvolvimento do jornalismo online, nesse mesmo período, pode ser uma forma de lançar alguma luz sobre o que estava acontecendo então e sobre a situação atual dos hipertextos literários na Internet.

Em 1995 os jornais online - diários e comerciais - começavam a sua escalada, passando de 20 em 1994, para 471 em 1995. Nesse mesmo ano de 1995. Melinda McAdams publicou um artigo que hoje pode ser considerado um marco da literatura sobre o Jornalismo na Internet: "Inventing an online newspaper", na qual ela compartilha e discute sua experiência de criação da 
versão online do Washington Post. A idéia de "jornal como metáfora", colocada e discutida por McAdams nesse trabalho, fornece uma das possíveis pistas para explicar as especificidades do desenvolvimento do formato jornalístico nos últimos dez anos, como procuraremos indicar mais adiante neste ensaio.

Em 1995 os hipertextos literários também se multiplicavam, e uma editora (Eastgate) especializava-se em sua distribuição em meio magnético (ou seja: em disquetes, naqueles dias pretéritos), enquanto sites iam sendo criado para a divulgação da produção literária hipertextual na Web. Um dos mais influentes, estabelecido também em 1995, foi o Hyperizons, um espaço voltado para a divulgação de textos de hiperficção e sua crítica. Hyperizons deixou de ser atualizado em 1997, mas ainda se encontra lá (com muitos links perdidos, como seria de se esperar) como um valioso testemunho da produção literária na web daquele período ${ }^{8}$.

Quase uma década depois, é essencial que se pergunte: O que aconteceu desde então? Os gêneros se firmaram? Até que ponto ocorreu o esperado desenvolvimento de linguagens próprias hipertextuais, tanto no âmbito da literatura quanto da escrita jornalística e de outras formas expressivas no ciberespaço?

Para começar, algo que causa surpresa e que pode ser indicativo das significativas diferenças observadas entre o desenvolvimento do texto jornalístico e da literatura na Web é justamente o fato de que uma busca no Google usando-se como palavra chave "hypertext literature" traz na cabeça da lista justamente o Hyperizons, com seus links (lamentavelmente) quebrados.

Outro site de grande influência nos meados da década de 90, o Hipertext Literature Online também aparece com proeminência quando fazemos hoje uma busca no Google. Mas sua última atualização data de setembro de 2000,

\footnotetext{
${ }^{8}$ Uma literatura de hiperficção brasileira também marcou presença na Internet, naquele período. Para alguns exemplos veja-se Tristessa (1998), de Marco Antonio Pajola (Passenger), Baile de Máscaras (1998), de Vera Mayra, e A Dama de Espadas (1998), de Marcos Palacios, dentre muitos outros. Na mesma época, cyber-novelas estavam em moda no site do UOL.
} 
quando seu webmaster, Jean Mason, terminou sua tese doutoral, cujo processo de produção alimentava o site.

A maior parte dos sites encontrados pelas buscas, usando-se palavras chaves similares, leva a uma constatação inevitável: há um maior número de trabalhos de crítica à produção hipertextual e suas potencialidades do que propriamente um corpus vivo e em transformação de obras literárias hipertextuais para consumo na Internet.

A vasta maioria das obras de ficção hipertextual disponibilizada na Internet tem data de produção situada justamente no período 1994/1999. De lá para cá não parece haver ocorrido muito movimento ou desenvolvimento nesse setor. O que aparentemente justifica a asserção de Curt Cloninger (2000), transcrita como epígrafe deste ensaio: "Ao fim e ao cabo, a literatura em hipertexto pode provar ser a realização da fantasia secreta dos críticos desconstrutivistas: um gênero literário mais conhecido por sua crítica, do que por sua literatura propriamente dita" (2000, p. 4).

Fazendo um balanço da situação da hiperficção em 2001, McGann (2001:17) afirma que "armados com impressionantes recursos técnicos, os trabalhos produzidos nesse novo gênero empalidecem em complexidade diante de seus antecessores em papel”.

Enquanto o número de jornais online (diários e comerciais) não cessou de crescer, como se pode verificar pelo gráfico abaixo, alcançando a marca de mais de quase cinco mil produtos diários e comerciais na Internet em 2001, distribuídos (muito desigualmente, é claro) pelos cinco continentes, a literatura hipertextual parece ter sofrido uma (pelo menos momentânea) estagnação. 


\section{compós}

\section{Número De Jornais Diários Online No Mundo}

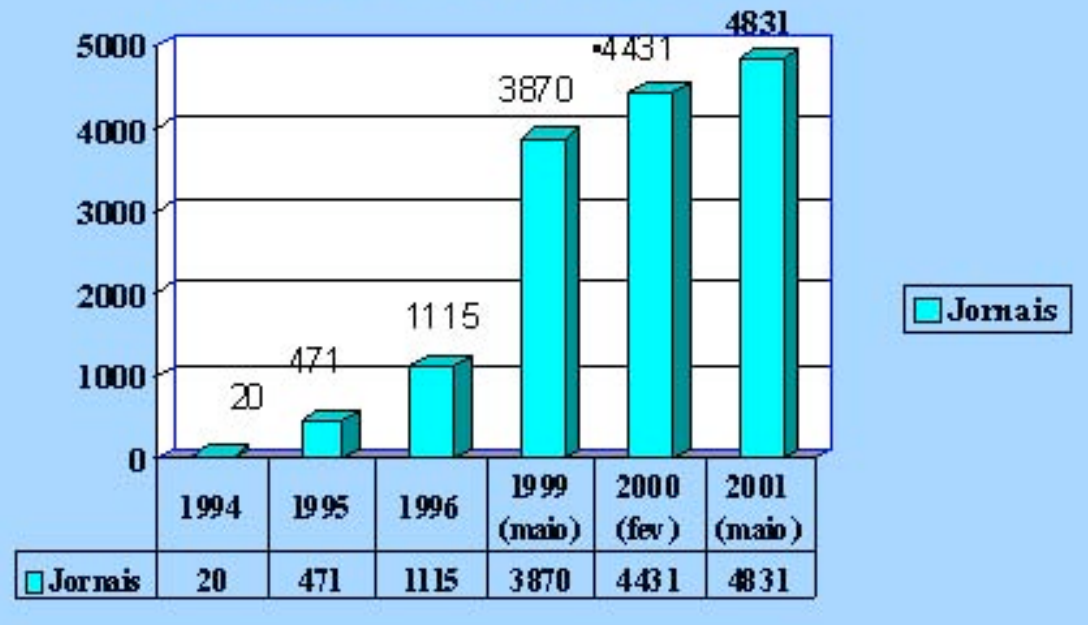

Forte: Editor \& Publisher-- Ittp:/iwww.mediainfo.com

Para iniciar uma discussão em torno das possíveis causas desse desenvolvimento diferenciado das duas tipologias discursivas, talvez um primeiro fator a ser apontado seja que, diferentemente da literatura, no jornalismo há uma história de convivência, mais ou menos harmoniosa, de diferentes formas expressivas, em diferentes suportes. Não, é claro, no sentido da convergência midiática que caracteriza a Internet, mas a produção jornalística, desde sua emergência em meio impresso, utiliza-se de imagens de variados tipos (gravuras, charges, fotos, infográficos, vinhetas etc) há mais de cem anos. Apesar de que seja possível identificar-se uma certa tensão entre texto e imagem, no processo de produção e veiculação da informação jornalística, o fato é que, em diferentes medidas e com diferentes propósitos, texto e imagem vêm sendo utilizados na quase totalidade de veículos impressos jornalísticos contemporâneos. Além disso, o discurso jornalístico adaptou-se aos suportes radiofônico e televisivo, incorporando e aproveitando 
as especificidades das novas tecnologias eletrônicas, sem perder sua identidade discursiva.

Muito mais que uma ruptura, para o jornalismo, a multimidialidade possibilitada pela Internet representa uma continuidade e uma potencialização de uma característica já estabelecida em suportes anteriores de produção e veiculação jornalística9.

Por outro lado, o mesmo não se pode dizer da literatura, caracterizada milenarmente por ser oral ou textual, em sentido estrito. É verdade que imagens foram usadas, ao longo da história da literatura, como reforço ou ilustração dos elementos textuais. No caso europeu, as imagens tiveram proeminência no período que antecede a invenção da imprensa, nos manuscritos iluminados, tanto sagrados quanto profanos ${ }^{10}$. A ilustração de obras literárias impressas não é uma prática incomum e até gozou de relativo prestígio em algumas épocas (na Inglaterra Vitoriana, por exemplo, era uma fórmula de grande aceitação, tanto na prosa quanto na poesia). No entanto, a literatura ilustrada não se impôs historicamente como uma prática generalizada. Pelo contrário, a literatura ilustrada apresenta-se hoje como excepcional, sendo mais corrente em formatos populares ou folhetinescos, em algumas “edições especiais” de obras magnas - como O Don Quixote, de Cervantes, a Divina Comédia, de Dante, O Paraíso Perdido, de Milton, as peças de Sheakespeare etc, que foram trabalhadas por notáveis ilustradores como Gustave Doré, William Blake, J. M. Turner, Salvador Dali e centenas de outros ${ }^{11}$ - e, evidentemente, na literatura infantil ${ }^{12}$, que prodigaliza imagens como forma de aproximar de seus leitores ao texto.

\footnotetext{
9 Para uma discussão dos conceitos de ruptura, continuidade e potencialização veja-se Palacios, Marcos. Ruptura, continuidade e potencialização no jornalismo on-line: o lugar da memória, in: Machado, Elias \& Palacios, Marcos. Modelos do Jornalismo Digital,

Salvador:Calandra, 2005.

${ }_{10}$ Uma excelente amostra de manuscritos iluminados pode ser apreciada na seção medieval da Web Gallery of Art em: http://www.wga.hu/frames-e.html?/html/zgothic/miniatur/1151200/index.html

${ }_{11}$ Em 2003, o Museu do Prado, em Madrid, organizou uma exibição especial dedicada aos ilustradores de Quixote. Em 2004, em Brasília, uma mostra reuniu 102 ilustrações de
} 
Não se registrou a emergência de um novo formato literário, produto da junção da literatura com a fotografia, a despeito de algumas incursões por esse caminho. Ocorre-nos o exemplo de Let us now praise famous men, de Walker Evans e James Agee, uma obra do final dos anos 30 (New York: Ballantines Book, 1939), espécie de híbrido ensaístico entre Literatura e Antropologia, com uso abundante de (excelentes) fotos de Walker Evans, um dos expoentes da fotografia-documentário nos anos 30. Mas a obra é certamente mais um contra-exemplo do que um exemplar de um sub-gênero.

Um aúdio-livro não é um híbrido, mas apenas uma gravação analógica ou digital de um texto, visando aqueles que não podem ou não querem ler, mas sim ouvir a obra. Por outro lado, uma história contada com imagens em movimento não é mais literatura, pois se torna cinema ${ }^{13}$, e a transposição para o formato de quadrinhos de uma obra literária, pode caracterizar um tipo ou sub-gênero dessa tipologia discursiva, mas dificilmente será aceita como "obra literária". O mesmo pode ser dito da adaptação de obras literárias para o formato televisivo. Diferentemente do jornalismo, portanto, o texto literário tende a perder sua identidade discursiva ao hibridizar-se com outros formatos midiáticos.

Mais importante ainda, no que se refere às especificidades da migração do jornalismo e da literatura para a Internet, são as diferenças dessas duas tipologias discursivas no que diz respeito à organização do fluxo da narrativa.

diferentes edições do livro, realizadas entre 1819 e 1971. As ilustrações de Gustave Doré para o Don Quixote, A Divina Comédia e Paraíso Perdido podem ser apreciadas em :

http://www.scathach.de/dore/quixote/dono1.htm , http://www.scathach.de/dore/dante/danteo1.htm e http://www.scathach.de/dore/paradise/paradis1.htm, respectivamente.

12 Em 2003, o Museu do Prado, em Madrid, organizou uma exibição especial dedicada aos ilustradores de Quixote. Em 2004, em Brasília, uma mostra reuniu 102 ilustrações de diferentes edições do livro, realizadas entre 1819 e 1971. As ilustrações de Gustave Doré para o Don Quixote, A Divina Comédia e Paraíso Perdido podem ser apreciadas em :

http://www.scathach.de/dore/quixote/dono1.htm , http://www.scathach.de/dore/dante/danteo1.htm e http://www.scathach.de/dore/paradise/paradis1.htm, respectivamente.

${ }_{13}$ No caso da Internet, o casamento feliz entre texto e imagens em movimento está ocorrendo no caso dos vídeo-games, que já constituem objeto de um campo específico de estudos de narratividade hipertextual e multimidiática. 
A idéia principal que lançamos para discussão neste ensaio é de que ao migrar para a Internet ${ }^{14}$, o jornalismo tinha no impresso uma metáfora facilmente utilizável (McAdams, 1995), debaixo da qual tem se desenvolvido nos últimos dez anos. O “jornal enquanto metáfora” presta-se, por sua própria natureza, à construção hipertextual. O que é uma chamada de primeira página senão um processo de linkagem para um texto localizado em outro(s) arquivo(s)? O leitor do jornal impresso já estava acostumado a ler hipertextualmente muito antes da existência do hipertexto. Ninguém lê um jornal como se lê um romance, da primeira à última linha.

Embutida na própria lógica do jornal 15 enquanto dispositivo ${ }^{16}$ há uma hipertextualidade pré-digital. O jornal impresso não é concebido e construído para ser lido linha por linha, da primeira à última página. Igualmente e coerentemente, a forma de consumo do produto jornalístico revela um comportamento hipertextual por parte do leitor, que pula das manchetes e chamadas da primeira página para a seção em que tem maior interesse, vai, volta, lê em diagonal, fica apenas no nível do lead de uma notícia, lê outra até o fim, olha uma foto e passa os olhos por uma legenda, descarta todo um suplemento pelo qual não se interessa, reserva para leitura posterior ou “arquivamento" uma página com um texto mais longo etc. Em alguns casos, um jornal totalmente desconjuntado e espalhado pelo chão é uma evidência palpável de tais comportamentos "hipertextuais" de leitura.

Por outro lado, à exceção de alguns casos isolados, que podem ser classificados como hipertextuais avant-la-lettre, como Rayuela de Julio Cortazar, o Dicionário Kazar, de Milorad Pavic, Em uma noite de inverno um viajante, de Ítalo Calvino, ou o famoso Cent Mille Milliards de Poémes, de Raymond Queneau (que aliás tem uma versão online), a literatura pré-digital caracterizou-se sempre por sua linearidade estrita, constituindo leitura

\footnotetext{
14 Para uma discussão sobre as características da Internet enquanto meio de comunicação e/ou ambiente de comunicação, veja-se Palacios 2003.

15 Naturalmente estamos falando do "jornal moderno", ou seja, de um modelo que está entre nós há quase 100 anos.

${ }_{16}$ Para uma discussão do jornal enquanto dispositivo veja-se Mouillaud (1997, p.2).
} 
transgressiva, qualquer tentativa de percorrer o texto de uma forma não seqüencial, como por exemplo dar uma espiada nas últimas páginas para saber se o mordomo é realmente o assassino...

Muito da discussão da década de 90 sobre as vantagens e os supostos avanços representados pelo hipertexto com relação à escrita tradicional centrou-se - e de alguma forma ainda se centra - na questão da Linearidade $\mathrm{x}$ Não Linearidade. No entanto, essa contraposição sempre nos pareceu um tanto equivocada.

Num texto produzido em 1999, seguindo a trilha de algumas idéias introduzidas por Gunnar Liestøl (1994), sugerimos que:

\begin{abstract}
A noção de "não-linearidade", tal como vem sendo generalizadamente utilizada, parece-nos aberta a questionamentos. Nossa experiência de leitura dos Hipertextos deixa claro que é perfeitamente válido afirmar-se que cada leitor, ao estabelecer sua leitura, estabelece também uma determinada "linearidade" específica, provisória, provavelmente única. Uma segunda ou terceira leituras do mesmo texto podem levar a "linearidades" totalmente diversas, a depender dos links que sejam seguidos e das opções de leitura que sejam escolhidas, em momentos em que a história se bifurca ou oferece múltiplas possibilidades de continuidade (Palacios 1999:5).
\end{abstract}

Concluíamos então, que muito mais que uma não-linearidade, estava em causa uma "Multi-linearidade do hipertexto, em contraposição à Unilinearidade do texto tradicional, ainda que, evidentemente, mesmo no texto tradicional Leituras Transgressivas sejam possíveis, criando Multilinearidades. Basta que se pense numa leitura transversal, que seleciona trechos e que "vai e volta", saltando ao longo do texto, sem que seja seguida a seqüência “canônica” pré-estabelecida pelo autor. Não é ocioso lembrar-se que a palavra browser, utilizada para designar os programas de leitura de hipertexto, provém do verbo pré-informático to browse, que significa (entre outras coisas) percorrer páginas a esmo, mas que tem uma raiz etimológica 
associada aos brotos ou ramificações na ponta da haste de uma planta ${ }^{17}$ (Ibidem, p.7).

A diferença aqui é que enquanto na literatura a construção multi-linear e a leitura transversal são transgressivas, no jornalismo elas são a norma. E como natura non facit saltum (a natureza não dá saltos) a migração das duas tipologias discursivas para a Internet funcionou no sentido de potencializar as características multi-lineares já existentes no jornalismo impresso, porém sem lograr, pelo menos até o presente, estabelecer um novo formato para a escrita literária, que fosse além dos experimentos iniciais e se estabilizasse como uma nova modalidade de prática narrativa.

Enquanto o jornal impresso representava uma metáfora altamente aproveitável para o jornalismo na web, passível de fazer usos das possibilidades de multilenearidade propiciadas pelo hipertexto nas redes digitais, a literatura não tinha modelos prévios que servissem como metáforas apropriadas. Ou antes, como aponta Cloninger (2000), tinha uma metáfora possível, porém das mais pobres, na idéia dos livros do tipo "faça sua própria história": "se quiser entrar em luta com o dragão vá para a página 72 "; "se quiser fugir com a donzela, pule para a página 287 .

Para Clonninger, o hipertexto funciona maravilhosamente como agregador da Internet num todo e como possibilitador do funcionamento da arte multimidiática, mas redunda em produtos extremamente pobres quando aplicados à literatura. Para ele "da mesma forma que Dadaísmo, algumas coisas funcionam melhor em teoria do que em sua execução. A idéia iconoclasta de Duchamp do urinol como arte é muito mais impressionante do que o urinol em si mesmo. E naturalmente era esse o ponto de Duchamp. Da mesma forma, teorias complexas sobre novelas interativas ou sobre poesia em fluxo contínuo de consciência (stream-of-consciousness enabled poetry) são muito mais interessantes de se ler do que os próprios poemas ou novelas hipertextuais" (2000, p.1).

${ }_{17}$ The Concise Oxford Dictionary, Oxford: Clarendon Press, 1990 edition. 
Estas notas neste breve ensaio certamente não fazem justiça à amplitude de experimentos em literatura hipermidiática e seria necessário entrarmos em detalhes e passarmos a análises específicas de produtos literários hipermidiáticos para nos aproximarmos de um julgamento mais acurado do que efetivamente aconteceu e vem acontecendo nesse campo. Mas é inegável que apesar do sucesso de algumas peças de hiperficção criadas nos últimos 10 ou 12 anos, o que mais se tem multiplicado na Internet, em termos literários, é a transposição pura e simples dos textos pré-digitais para arquivos digitais, desde o pioneiro Projeto Gutenberg a bibliotecas de obras literárias clássicas, em latim, grego, aramaico, o que se queira.

Michael Joyce assinala que no Voice of the Shuttle, um site-portal para Humanidades em geral, o item Recursos sobre Literatura Inglesa abre uma lista "de cerca de trinta e seis e meia polegadas lineares de links, e isso sem contar as áreas sub-disciplinares.”(2004, p.78) A herança cultural literária, em todas as línguas e de todos os tempos, está sendo digitalizada e magicamente colocada a nosso alcance, numa renovação potencializada do sonho de Alexandria. Mas, até momento, poucos textos literários pós-digitais hipermidiáticos parecem ter vindo para ficar, a não ser talvez como curiosidades experimentais de um momento de transição.

Obras bastante complexas, criativas e instigantes têm sido produzidas sobre as potencialidades e o futuro de uma literatura hipermidiática, como o Hamlet on the Holodeck, de Janet Murray (1998), as elucubrações de MarieLaure Ryan (2001) sobre narrativa e realidade virtual, ou as quase-receitas altamente ilustradas de Mark Meadows (2002) sobre como realizar o salto hipermidiático. Paradoxalmente, no entanto, produtos com as características elencadas em tais obras parecem estar mais próximos de emergir - e serem prazerosamente consumidos - em forma jornalística do que literária. A despeito das limitações e dos riscos apontados por Saad (2004), o jornalismo na Internet aparece como um espaço de experimentações, - com maior ou 
menor sucesso, com maior ou menor permanência, com maior ou menor ousadia e criatividade. Como um espaço pulsante, enfim.

Até muito recentemente, as potencialidades abertas pela Web para o jornalismo ressentiam-se de uma grave limitação tecnológica: as baixas velocidades de conexão. Até o advento da chamada Banda Larga (que ainda está longe de se generalizar, especialmente em países/regiões periféricas), baixar uma foto de tamanho médio (150 pixels x 150 pixels) usando um modem de pequena capacidade e uma linha telefônica era uma enervante operação, que podia levar vários minutos, na hipótese de ser bem sucedida, uma vez serem freqüentes as "quedas de conexão" e outros acidentes de percurso. Era comum os sites oferecerem alternativas de versões text only (somente texto, com exclusão fotos e outras imagens) para usuários conectados a baixas velocidades. Tal situação, evidentemente, restringia a utilização não só de fotos, mas de todo o qualquer recurso não textual, fazendo dos sites, de um modo geral, (hiper)textos num sentido estrito, complementados subsidiaria e optativamente por outras mídias, a depender das possibilidades de conexão dos usuários.

Tal limitação essencial condicionava o segundo fator de restrição ao uso de imagens: o pouco desenvolvimento do design e de linguagens específicas e adequadas para o novo suporte. A limitação técnica funcionava, portanto, como um desestímulo à experimentação e ao uso dos recursos potenciais oferecidos pelo novo suporte, mantendo a metáfora do jornal impresso em seu lugar.

Porém a metáfora não impedia, mas antes pelo contrário potencializava, a hipertextualidade, um recurso que independia de altas velocidades de conexão. Superada a fase primitiva de transposição pura e simples das edições impressas para a web ${ }^{18}$, o jornalismo na Internet frutificou sob o manto

\footnotetext{
${ }^{18}$ A transposição plena tem voltado como opção: alguns sites jornalísticos comerciais oferecem, para assinantes, a possibilidade de acesso em PDF à versão integral do jornal impresso. É o caso, por exemplo, de O Estado de São Paulo que oferece tais serviços para seus assinantes.
} 
protetor da metáfora e o comportamento hipertextual do leitor encontrou plena ressonância nos meandros das edições online.

O advento das conexões rápidas e sua disseminação crescente estão abrindo novas possibilidades para uma utilização efetivamente multimediática da Internet, e para novas formas de incorporação da imagem e do áudio ao produto jornalístico na web. A banda larga soma-se à flexibilidade já oferecida pela digitalização, modularização e variabilidade dos formatos midiáticos (Manovich, 2001), possibilitando que se caminhe, de facto, em direção a um Jornalismo On-line com hipertextualidade, no sentido amplo que Landow (1997) e outros emprestam ao conceito.

É igualmente no texto jornalístico, através de experimentos como $\underline{\text { Indymedia, }}$ Slashdot, $\underline{\text { Kuro5hin, }}$ Discordia etc - e dos Blogs coletivos de um modo geral -, que o conceito de hipertexto coletivo, um dos ícones dos experimentos da hiperficção na década de 90 vai se materializando com sucesso. Enquanto obras ficcionais coletivas como Citythreads, ou The Madame de Lafayette Book of Hours rapidamente perderam interesse ${ }^{19} \mathrm{e}$ deixaram de ser visitadas e atualizadas, o Indymedia conta com mais de 140 sites (coletivos) espalhados pelo mundo. E em plena atividade e produção. No Slashdot, o leitor não apenas se torna também produtor de informação, mas a quantidade de acessos e os comentários às notícias disponibilizadas funcionam como mecanismo de hierarquização do material noticioso.

Uma observação dos maiores jornais internacionais (incluídos aqui os brasileiros como a Folha de São Paulo e $\underline{\mathrm{O} \text { Estado de São Paulo) }}{ }^{20}$ leva à constatação de que, ainda que mantendo basicamente a idéia da metáfora, o

\footnotetext{
19 Um dos mais famosos hipertextos coletivos de meados dos anos 90, o Hotel de Robert Coover, criado como parte de uma Oficina de Hipertexto da Brown University, não é mais encontrado na Internet, sequer como um "museu" no Wayback Machine, a máquina do tempo da Web. Referências ao Hotel são encontradas, é claro, enquanto objeto de textos de crítica literária....

20 Vide: Munhoz, Paulo \& Palacios, Marcos. The Uses of Photography in the On-line Journalism of the Major Newspapers of Brazil and the United States: elements for comparison, trabalho apresentado no Colóquio Brasil Estados Unidos, Austin University, Texas, 2004.
} 
jornalismo online, através do uso crescente de bancos de dados, começa realmente a entrar no que convencionou chamar "terceira fase" do jornalismo online, apesar de que não haja entre os diversos autores um consenso quanto ao que caracterizaria, prioritária ou determinantemente tal estágio. Seria a terceira fase caracterizada pela pauta aberta? (Brown \& Chignell, 1997); pela ampla utilização de bancos de dados? (Machado 2004, Barbosa 2004, Fidalgo 2003, Koch 1991); maior Interactividade?; maior Personalização? (Bonnet, 2001; Pryor, 2002); maior atenção para com o Local (Garcia, 2000); ou tudo isso e algo mais?

Talvez ainda seja cedo para um julgamento definitivo, quanto ao desdobramento promissor do hipertexto jornalístico na web e o relativo fracasso do hipertexto de ficção. Santos (2002) aponta em direção a coisas por vir:

\begin{abstract}
"Em linhas gerais, o que se deve discutir, com respeito aos hipertextos eletrônicos, é a maneira como a materialidade deles se proteifica e se permite percursos e desenhos de leitura e de navegação que colocam em xeque as fronteiras habituais entre real e virtual, espacial e temporal. E mais, para a criação literária (e para toda arte que ainda vislumbra alguma chance de aprender com a criação verbal), essas possibilidades todas apontam para outro duplo movimento, o de versificação da prosa e de prosificação do verso. São dicotomias que perseguem a leitura no(do) espaço eletrônico, permitindo entendê-lo sob a perspectiva de lógicas plurais e dinâmicas, sempre assentadas num espaço, esse do transbordo dos significantes e dos significados, mas sem reduzir-se a fórmulas prontas, a essências ideais, a gestos desprovidos de temporalidade e prenhes de relativismo. Tais duplicidades podem ser a maneira mais próxima de uma racionalidade plural, a ser associada aos textos eletrônicos”.(SANTOS 2002)
\end{abstract}

Aspen Aarseth (2003) porém aponta para algumas outras evidências, que podem indicar que outras portas estão se abrindo para o texto eletrônico que não necessariamente as que conhecíamos até então:

"Pode ser muito cedo para passar-se um julgamento sobre o sucesso cultural do hipertexto, uma vez que mudanças culturais são muito mais lentas que inovações tecnológicas. Tipicamente, 


\begin{abstract}
levou cinqüenta anos desde a inovação de Gutenberg para que os livros passassem de uma simulação de um manuscrito para os artefatos que nós hoje conhecemos. Talvez a idéia de (Ted) Nelson de uma escrita não seqüencial seja adotada por uma geração que lê a maioria de seus textos online, e para a qual a impressão em papel parecerá graciosamente antiquada e ornamental, um pouco como as inscrições em pedra nos parecem hoje. No entanto, essa geração já está ativa por aqui e os textos que eles usam são digitais e interativos de uma maneira que Nelson não imaginou. Hoje, a linguagem escrita de nossa geração mais jovem é formatada não pelo hipertexto, mas pelo SMS (mensagens curtas - "torpedos" - de telefones celulares) um sucesso totalmente inesperado da tecnologia de telefonia móvel (GSM) (...) Os códigos lingüísticos desse meio (por exemplo CUL8R para "see you later") contaminam outros gêneros textuais, para desespero de pais e professores. Mas o sucesso sociolingüístico do SMS enquanto meio indica-nos que há uma mudança real na prática e na história da escrita, que, diferentemente do hipertexto radical, e num tempo muito mais curto, já aconteceu" (ARSETH, 2003)
\end{abstract}

E Aarseth conclui, como também nós aqui concluímos este ensaio, que, muito provavelmente, o modo hipertextual de ler e escrever encontrará formas e caminhos, literários e não literários, e se firmará como modalidade de produção simbólica. Não como um modo dominante na Web e fora dela, mas como uma entre muitas formas, algumas antiqüíssimas e outras ainda (por)vir.

\title{
Referências:
}

AARSETH, Aspen. The Hypertext Revolution, 2003, disponível em: http://www.educ.fc.ul.pt/hyper/resources/eaarseth.htm

AUERBACH, Sarah. Ficción hipertextual: uma teoria literária, 1995, disponível em: http://www.ucm.es/info/especulo/hipertul/auerbach.html BARBOSA, Suzana. Banco de dados como metáfora para o jornalismo digital de terceira geração. In: VI Lusocom, Covilhã, abril 2004, disponível em http://www.cccc2004.ubi.pt/

BELLEI, Sérgio Luís Prado. O fim do livro e o livro sem fim, Revista Brasil de Literatura, ano IV, 2002, disponível em: http://members.tripod.com/ lfilipe/bellei.html BONETT, M. Personalization of Web Services: opportunities and challenges, 2002, disponível em: http://www.ariadne.ac.uk/issue28/personalization/ BROWN, Edward y CHIGNELL, Mark H. El usuario como diseñador: el multimedia de forma abierta. In: Medios contextuales en la práctica cultural Barcelona: Piados, 1997. 
CHARTIER, Roger. A aventura do livro do leitor ao navegador, São Paulo: Ed. da UNESP, 1998

CLONINGER, Curt. Don't believe the hype(rtext): a meta-meta-criticism of meta criticism, 2000, disponível em: http://www.sparkonline.com/novemberoo/discourse/cloninger.html

CORREA, Elizabeth Saad. Linguagens da informação digital: reflexões conceituais e uma proposta de sistematização In: III SOPCOM, Covilhã, abril 2004, disponível em http://www.cccc2004.ubi.pt/

FAUTH, Jürgen. Poles in Your Face: The Promises and Pifalls of Hyperfiction, in: Mississippi Review, June 1995, The Center for Writers, The University of Southern Mississippi, disponível em:

http://www.uoc.edu/in3/hermeneia/sala_de_lectura/j_fauth_poles_in_your face.htm

FIDALGO, Antonio. Sintaxe e semântica das notícias on-line. Para um jornalismo em base de dados. XII Encontro Nacional dos Programas de Pós Graduação em Comunicação (COMPÓS), Recife, junho de 2003, disponível em: http://bocc.ubi.pt

GARCÍA, Xosé Lopez. La comunicación Del futuro se escribe con L de local. In: Revista Ámbitos, No 5, 2000. Disponível em:

www.ull.es/publicaciones/latina/ambitos/ambitos.htm

KOCH, Tom. Journalism in the 21 st. Century. Online information, electronic databases in the news. London: Adamantine Press, 1991.

LIESTØL, G. Wittgestein, Genette, and the Reader's Narrative in Hypertext, in: LANDOW, G. (Org.) HyperText Theory, Baltimore: John Hopkins, 1994, pp. 87-120

MACHADO, Elias. Banco de dados como formato no jornalismo digital. In: III SOPCOM, Covilhã, abril 2004, disponível em: http://www.cccc2004.ubi.pt/ MANOVICH, Lev. The Language of New Media, Massachiusetts: MIT Press, 2001.

LANDOW, G. P. Hypertext 2.0: the convergence of contemporary critical theory and technology, Baltimore: The Johns Hopkins University Press, 1997. MAINGUENEAU, Dominique. Análise de textos de comunicação. São Paulo: Cortez, 2001.

MANGUEL, Alberto. Uma história da leitura, São Paulo: Cia. das Letras, 1997. McADAMS, Melinda. Inventing an Online Newspaper, in: Interpersonal Computing and Technology: an electronic journal for the 21 st century, July 1995, Volume 3, Number 3, pp. 64-90. Disponível em: http:// www.sentex.net/\%7Emmcadams//invent.html McGANN, Jerome. Radiante textuality: literature after the world wide web, New York: Palgrave, 2001.

MEADOWS, Mark. Pause \& Effect - The Art of Interactive Narrative, New Riders Publishing, 2002

MIELNICZUK, Luciana \& PALACIOS, Marcos. Considerações para um estudo sobre o formato da notícia na Web: o link como elemento paratextual. Disponível em: http://www.facom.ufba.br/jol/producao.htm 
MOUILLAUD,Maurice. Da forma ao sentido, in: Mouillaud, Maurice e Porto, Sérgio Dayrell (Orgs) O Jornal da forma ao sentido, Brasília: Paralelo 15, 1997. MUNHOZ, Paulo \& PALACIOS, Marcos. The Uses of Photography in the Online Journalism of the Major Newspapers of Brazil and the United States: elements for comparison, trabalho apresentado no Colóquio Brasil Estados Unidos, Austin University, Texas, 2004.

MURRAY, Janet. Hamlet on the Holodeck: the future of narrative in Cyberspace, Massachussets: MIT University Press, 1998.

PALACIOS, Marcos. Hipertexto, Fechamento e o uso do conceito de nãolinearidade discursiva, in:.Lugar Comum, Rio de Janeiro, n. 08, p. 111-121, 1999. Originalmente apresentado no Encontro Nacional da COMPÓS, Belo Horizonte, 1999, disponível em:

http://www.facom.ufba.br/jol/producao.html

Internet as System and Environment in Cyberspace:

Preliminary Ideas from an Ongoing, in TripleC, vol. 1, n. 2, 2003, disponível em http://triplec.uti.at/articles

Jornalismo Online: Ruptura, Continuidade e Potencialização no

o Lugar da Memória, in: MACHADO, Elias \& PALACIOS, Marcos (Orgs), Modelos do Jornalismo Digital, Salvador: Editora Calandra, 2003, disponível em: http://www.facom.ufba.br/jol/producao.htm

PRYOR, Larry. The third wave on online journalism, Online Journalism Review, April, 2002, in: http://www.ojr.org/ojr/future/1019174689.php RYAN, Marie-Laure. Narrative as Virtual Reality: Immersion and Interactivity in Literature and Electronic Media, Baltimore: Johns Hopkins Univ Press, 2001.

SANTOS, Alckmar Luiz dos. Transbordos e reformatações do texto eletrônico, disponível em: http://wawrwt.iar.unicamp.br/GTcompos2002/alckmar.html 